\title{
Physico-mechanical and thermophysical properties of composites based on secondary polypropylene modified with ultra-high molecular weight polyethylene
}

\author{
A. R. Sadritdinov ${ }^{\dagger}$, E. M. Zakharova, A. G. Khusnullin, V.P. Zakharov \\ †aynur.sadritdinov@mail.ru
}

Bashkir State University, 32 Zaki Validi St., Ufa, 450076, Russia

\begin{abstract}
The relevance of the problem under study is due to the development of a method for the rational use of polypropylene-based polymer waste (PP) by creating polymer composites in a mixture with ultra-high molecular weight polyethylene (UHMWPE). The article is aimed at studying the physico-mechanical and thermophysical characteristics of polymer composites based on PP and UHMWPE. The leading research methods for this problem are the study of the strength characteristics of polymer composites at break and bending, thermogravimetric analysis and differential scanning calorimetry. It is shown that the maximum torque in the mixing chamber during polymer melting does not additively change depending on the composition of the mixture. The increase in maximum torque more than 2 times occurs when filling the secondary polypropylene $5 \%$ of the mass. UHMWPE and only $25-35 \%$ decreases when filling UHMWPE with polypropylene in an amount of $10-50 \%$ of the mass. Filling of secondary UHMWPE polypropylene up to $3 \%$ of the mass slightly strengthens the composition, and also increases its modulus of elasticity at break and bending. UHMWPE allows increasing the thermal stability of secondary polypropylene by increasing the decomposition onset temperature by $12^{\circ} \mathrm{C}$, the mass of the residue upon heating to $400^{\circ} \mathrm{C}$, and peak displacements corresponding to the maximum decomposition rate of the main substance in the high temperature region. Two endothermic peaks corresponding to the melting temperature of the starting polymers are observed in the DSC thermogram in the heating mode; the melting temperature of polypropylene in the composite is $3.1-4.8^{\circ} \mathrm{C}$ lower than that of an individual polymer. The crystallization of PP and UHMWPE in the mixture proceeds in the same temperature range and is characterized by the presence of one exothermic maximum on the DSC curve, which is shifted to the temperature region corresponding to the crystallization temperature of an individual UHMWPE.
\end{abstract}

Keywords: secondary polypropylene, ultrahigh molecular weight polyethylene, tensile strength, thermogravimetric analysis, differential scanning calorimetry.

УДК: 678:539.424:536.54

\section{Физико-механические и теплофизические свойства композитов на основе вторичного полипропилена, модифицированного сверхвысокомолекулярным полиэтиленом}

\author{
Садритдинов А.Р. ${ }^{\dagger}$, Захарова Е. М., Хуснуллин А. Г., Захаров В. П. \\ Башкирский государственный университет, ул. Заки Валиди, 32, Уфа, 450076, Россия
}

\begin{abstract}
Актуальность исследуемой проблемы обусловлена разработкой способа рационального использования полимерных отходов на основе полипропилена (ПП) за счет создания полимерных композитов в смеси с сверхвысокомолекулярным полиэтиленом (СВМПЭ). Статья направлена на изучение физико-механических и теплофизических характеристик полимерных композитов на основе ПП и СВМПЭ. Ведущими методами исследования данной проблемы являются изучение прочностных характеристик полимерных композитов при разрыве и изгибе, термогравиметрический анализ
\end{abstract}


и дифференциальная сканирующая калориметрия. Показано, что максимальный крутящий момент в смесительной камере при плавлении полимеров не аддитивно изменяется в зависимости от состава смеси. Рост максимального крутящего момента более чем в 2 раза происходит при наполнении вторичного полипропилена 5\% масс. СВМПЭ и только на 25-35\% снижается при наполнении СВМПЭ полипропиленом в количестве 10 - $50 \%$ масс. Наполнение вторичного полипропилена СВМПЭ до 3\% масс. незначительно упрочняет композицию, а также повышает ее модуль упругости при разрыве и изгибе. СВМПЭ позволяет повысить термостабильность вторичного полипропилена за счет увеличения температуры начала разложения на $12^{\circ} \mathrm{C}$, массы остатка при нагреве до $400^{\circ} \mathrm{C}$, смещения пиков, соответствующих максимальной скорости разложения основного вещества в высокотемпературную область. На термограмме ДСК в режим нагрева наблюдаются два эндотермических пика, соответствующих температуре плавления исходных полимеров, при этом температура плавления полипропилена в композите на $3.1-4.8^{\circ} \mathrm{C}$ ниже, чем у индивидуального полимера. Кристаллизация ПП и СВМПЭ в смеси протекает в одном температурном диапазоне и характеризуется наличием одного экзотермического максимума на кривой ДСК, который смещен в область температуры, соответствующей температуре кристаллизации индивидуального СВМПЭ.

Ключевые слова: вторичный полипропилен, сверхвысокомолекулярный полиэтилен, прочность при разрыве, термогравиметрический анализ, дифференциальная сканирующая калориметрия.

\section{1. Введение}

Полипропилен (ПП) является одним из наиболее распространенных термопластичных полимеров, получившим распространение для приготовления широкого ассортимента пластмассовых изделий. В мировых масштабах производство полипропилена достигает $20 \%$ от общего объема полимеров, что определяет соответствующую величину отходов от всех имеющихся синтетических полимерных материалов в составе твердых бытовых отходов. Наиболее перспективным способом рационального использования вторичных полимеров на основе полипропилена является создание полимерных композитов $[1,2]$, в том числе на основе смесевых полимерных компаундов. Перспективным полимером для модификации полипропилена является сверхвысокомолекуярный полиэтилен (СВМПЭ) - высокоэффективный материал, обладающий отличной износостойкостью и ударной вязкостью по сравнению с другими полимерами [3]. Хорошая биосовместимость, химическая стойкость, высокая прочность при растяжении (41.3 МПа) и высокая кристалличность (более 90\%) определяет широкое применение СВМПЭ в медицине [4], автомобильной промышленности $[5,6]$. Высокая ударопрочность и трещиностойкость СВМПЭ обусловливают его потенциальную возможность для упрочнения полипропилена [7-10]. В то же время, высокое различие в вязкости между ними приводит к образованию крупных агломератов СВМПЭ и ухудшению механических свойств композитов.

Ввиду того, что полипропилен и сверхвысокомолекулярный полиэтилен являются термодинамически несовместимыми полукристаллическими полимерами, то приготовление полимерных компаундов на их основе должно приводить к различию теплофизических характеристик полимерных композитов по сравнению с исходными компонентами. [11-15].

Целью настоящей работы являлось изучение физико-механических и теплофизических характеристик полимерных композитов на основе вторичного полипропилена в смеси со сверхвысокомолекулярным полиэтиленом.

\section{2. Экспериментальная часть}

В работе использовали вторичный полипропилен, представляющий собой дробленый материал некондиционных пластмассовых изделий, производимых методом литья под давлением из гомополимера полипропилена марки PP H350 FF/3. Для приготовления композитов на основе вторичного полипропилена использовали первичный СВМПЭ марки ТУ 2211-06870353562-2006.

Приготовление композитов осуществляли гомогенизацией в смесительной камере лабораторной станции (пластограф) «Plastograph EC» (Brabender) при температуре $180^{\circ} \mathrm{C}$, скорости вращения шнеков 30 об/мин в течение 15 мин при нагрузке $200 \mathrm{H}$.

Опытные образцы получали методом литья под давлением на инжекционной формовочной машине Babyplast 6/10Р при температуре по зонам $225^{\circ} \mathrm{C}, 235^{\circ} \mathrm{C}$, $220^{\circ} \mathrm{C}$, давлении впрыска 65 bar, скорости впрыска $30 \%$, усилии смыкания 35 bar. Температура подачи охлаждающей воды в пресс-форму составляла $12^{\circ} \mathrm{C}$, время выдержки в пресс-форме - 10 с.

Физико-механические свойства опытных образцов при разрыве и статическом изгибе определяли согласно ГОСТ 11262-2017 и ГОСТ 4648-2014, соответственно, на универсальной испытательной машине Shimadzu AGS-X при температуре $23^{\circ} \mathrm{C}$, скорости движения подвижного захвата $1 \mathrm{mм/мин} \mathrm{при} \mathrm{определении} \mathrm{модуля}$ упругости и 5 мм/мин при определении других характеристик.

Для анализа термических характеристик полимерных композитов использовали методы термогравиметрического анализа (ТГА) и дифференциальной сканирующей калориметрии (ДСК). Исследования полимерных образцов проводили при следующих условиях:

ТГА - интервал температур $25-600^{\circ} \mathrm{C}$, динамический режим - скорость нагрева 5 град/мин, среда - воздух, прибор TGA-DSC («Mettler Toledo», Швейцария);

ДСК - интервал температур $40-200^{\circ} \mathrm{C}$, динамический режим - скорость нагрева/охлаждения 10 град/мин, среда - воздух, прибор DSC-1 («Mettler Toledo», Швейцария). 
Для оценки термической устойчивости полимеров в работе использовали следующие характеристики: $T_{\text {н }}$ - температура начала разложения полимера, соответствует началу снижения массы образца при нагревании; $T_{1}, T_{5}$ - температуры, соответствующие разложению полимера на $1 \%$ и $5 \%$ от первоначального значения массы; остаток после нагрева образца до температур $400^{\circ} \mathrm{C}$ и $600^{\circ} \mathrm{C}$ - параметры, которые использовались для характеристики процесса деструкции полимера и оценки наличия в полимере термически устойчивых примесей или добавок; $T_{\text {пл }}, T_{\text {кр }}$ - температуры плавления и кристаллизации полимерной фазы, соответствуют максимуму пика на кривой ДСК; $\Delta H_{\text {пл' }}$ $\Delta H_{\text {кр }}$ - энтальпии плавления и кристаллизации полиме$\mathrm{pa} ; T_{\max }$ - температура, соответствующая максимальной скорости разложения полимера, определяемая максимумом на дифференциальной кривой термогравиметрического анализа (ДТГ).

\section{3. Обсуждение результатов}

В процессе приготовления полимерных композитов в смесительной камере пластографа до момента полной пластикации (плавления) исходных полимеров величина крутящего момента увеличивается и при определенном времени достигает своего максимального значения. Затем, по мере прогрева и «саморазогрева» смеси полимеров вязкость композиции снижается, и по истечении 15 мин фиксируется минимальный крутящий момент, который коррелирует с текучестью расплава. Для рассмотренных композитов наблюдается неаддитивное изменение максимального крутящего момента в зависимости от состава полимерной смеси. Максимальный крутящий момент, характеризующий сопротивление при вращении шнеков смесительной камеры в процессе плавления, для исходных полимеров практически совпадает и находится на уровне 53 Н·м. Добавление 5\% масс. СВМПЭ к вторичному полипропилену приводит к увеличению значений максимального крутящего момента до $110 \mathrm{H} \cdot$ м. При содержании СВМПЭ в смеси более 10 мас.\% величина максимального крутящего момента снижается до $80 \mathrm{H} \cdot \mathrm{M}$ и стабилизируется на этом уровне до состава смеси ПП/СВМПЭ=50/50. Добавление $10-50$ мас.\% вторичного полипропилена к СВМПЭ приводит к снижению величины максимального крутящего момента до 35 - 40 Н · м.

Значения минимального крутящего момента, характеризующего текучесть расплава полимера, для вторичного ПП $(2.5 \mathrm{H} \cdot \mathrm{м})$ и СВМПЭ $(18.5 \mathrm{H} \cdot \mathrm{м})$ отличаются между собой достаточно сильно и коррелируют с величиной молекулярных масс. Значения минимального крутящего момента меняются практически аддитивно в интервале содержания СВМПЭ в смеси до 50 мас.\%. Добавление к СВМПЭ вторичного полипропилена в объеме до 50 мас.\% снижает текучесть расплава полимерной смеси по сравнению с аддитивной величиной на 30 - 80\%, что, очевидно, обусловлено нарушением сцепления молекул СВМПЭ за счет внедрения между ними ПП [12] и используется для повышения технологичности переработки СВМПЭ $[9,11]$.
Наполнение вторичного полипропилена СВМПЭ в количестве до 3 мас.\% приводит к незначительному упрочнению композиции, проявляющемуся в повышении прочности при разрыве (Рис. 1). При дальнейшем росте содержания сверхвысокомолекулярного полиэтилена в смеси прочность при разрыве снижается с $25.5 \mathrm{MПа}$ для вторичного полипропилена до 6 МПа для композиции, содержащей 20 мас.\% СВМПЭ. Аналогичным образом происходит изменение удлинения при разрыве (Рис. 1). Удлинение при разрыве вторичного полипропилена достигает величины 588\%, а композит, содержащий 1-5 мас.\% СВМПЭ, разрывается при удлинении 641-712\%. Дальнейший рост степени наполнения вторичного полипропилена характеризуется снижением эластичности компаунда, и при содержании СВМПЭ 20 мас.\% удлинение при разрыве составляет только 9\%.

Модификация вторичного полипропилена СВМПЭ приводит к увеличению жесткости полимерного компаунда, которая характеризуется модулем упругости. Модуль упругости при разрыве вторичного полипропилена равен 1100 МПа (Рис. 2), он увеличивается практически в два раза для композита, содержащего 20 мас.\% СВМПЭ. Модуль упругости при изгибе также растет от 925 МПа для вторичного полипропилена до 1028 МПа для композита, содержащего 10 мас.\% СВМПЭ (Рис. 2). При последующем увеличении количества СВМПЭ в композите модуль упругости при разрыве и модуль упругости при изгибе уменьшается.

Анализ теплофизических характеристик полимеров показал, что исходный СВМПЭ характеризуется более высокой термостабильностью $\left(T_{\text {н }}=247^{\circ} \mathrm{C}\right)$ по сравнению с вторичным полипропиленом $\left(T_{\mathrm{H}}=235^{\circ} \mathrm{C}\right)$. Это проявляется в том, что температуры $T_{\text {н }}$ и $T_{1}$ для СВМПЭ выше, соответственно, на 12 и $16^{\circ} \mathrm{C}$ по сравнению с вторичным ПП (Табл. 1). По этой причине значения параметров $T_{\text {н }}, T_{1}$ и $T_{5}$, полученные для композитов на основе СВМПЭ различного состава, выше аналогичных параметров для индивидуального полипропилена.

Сравнительная оценка параметров термического разложения полимерных композитов показала следующее (Табл. 1):

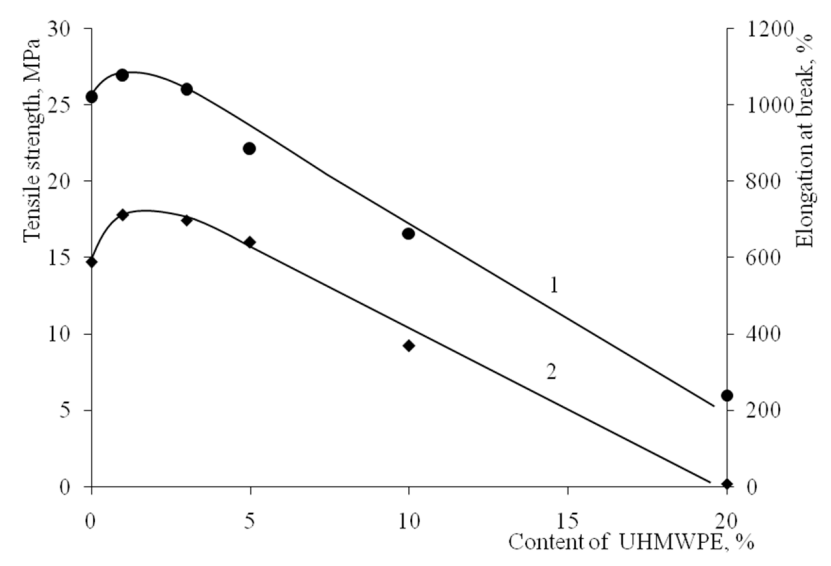

Рис. 1. Зависимость прочности (1) и удлинения (2) при разрыве от содержания СВМПЭ в композите.

Fig. 1. The dependence of the strength (1) and elongation (2) at break from the content of UHMWPE in the composite. 
Табл. 1. Результаты термогравиметрического анализа композитов ПП-СВМПЭ.

Table 1. Results of thermogravimetric analysis of PP-UHMWPE composites.

\begin{tabular}{|c|c|c|c|c|c|c|c|}
\hline \multirow{2}{*}{$\begin{array}{c}\text { Содержание } \\
\text { СВМПЭ, мас.\% } \\
\text { The content of } \\
\text { UHMWPE, wt.\% }\end{array}$} & \multirow{2}{*}{$\begin{array}{l}T_{\mathrm{H}}{ }^{\circ} \mathrm{C} \\
T_{\mathrm{b}},{ }^{\circ} \mathrm{C}\end{array}$} & \multirow{2}{*}{$T_{1},{ }^{\circ} \mathrm{C}$} & \multirow{2}{*}{$T_{5},{ }^{\circ} \mathrm{C}$} & \multicolumn{2}{|c|}{$\begin{array}{c}\text { Остаток, \% } \\
\text { Residue,\% }\end{array}$} & \multirow{2}{*}{$\begin{array}{c}T_{\max } \text { на ДТГ, }{ }^{\circ} \mathrm{C} \\
T_{\max } \text { on DTG, }{ }^{\circ} \mathrm{C}\end{array}$} & \multirow{2}{*}{$\begin{array}{c}\text { Снижение } \\
\text { массы, \% } \\
\text { Weight } \\
\text { reduction, \% }\end{array}$} \\
\hline & & & & $\begin{array}{c}\text { при } 400^{\circ} \mathrm{C} \\
\text { at } 400^{\circ} \mathrm{C}\end{array}$ & $\begin{array}{c}\text { при } 600^{\circ} \mathrm{C} \\
\text { at } 600^{\circ} \mathrm{C}\end{array}$ & & \\
\hline 0 & 235 & 254 & 269 & 4.54 & 1.79 & 320 & 95.9 \\
\hline 45 & 237 & 253 & 274 & 45.62 & 0 & 378 & 53.8 \\
\hline 50 & 233 & 258 & 284 & 30.47 & 1.89 & 360 & 98.7 \\
\hline 60 & 234 & 261 & 292 & 31.97 & 2.33 & 366 & 46.6 \\
\hline 90 & 258 & 268 & 317 & 91.55 & 1.97 & 411 & 87.7 \\
\hline 100 & 247 & 270 & 327 & 92.65 & 2.02 & 402 & 59.3 \\
\hline
\end{tabular}

- масса остатка после нагрева композитов до температуры $400^{\circ} \mathrm{C}$ существенно увеличивается по сравнению с аналогичным параметром для чистого полипропилена (4.5\%) и составляет от 30 до $92 \%$. В отличие от ПП, разложение которого происходит преимущественно в области температур до $400^{\circ} \mathrm{C}$, термоокислительная деструкция композитов на его основе смещена в более высокотемпературную область;

- наблюдается смещение пиков на кривых ДТГ композитов, характеризующих максимальную скорость разложения основной массы образца ( $T_{\max }$ на ДТГ), в область более высоких температур, по сравнению с исходным ПП.

Полученные результаты указывают на снижение скорости разложения ПП в присутствии СВМПЭ и смещение процесса разложения композитов в область более высоких температур. Введение СВМПЭ, обладающего более высокой термической устойчивостью по сравнению с ПП, способствует повышению термостабильности смеси полимеров в целом.

На термограммах ДСК образцов смесей полимеров ПП-СВМПЭ в режиме нагрева фиксируются два эндотермических пика плавления, соответствующих каждому из полимерных компонентов: СВМПЭ $\left(135.0-136.7^{\circ} \mathrm{C}\right)$ и ПП $\left(164.0-165.7^{\circ} \mathrm{C}\right)$ (Табл. 2, Рис. 3). Значения $T_{\text {пл' }}$ соответствующие СВМПЭ в полимерных смесях, близки к аналогичному значению для исходного полимера $\left(135.7^{\circ} \mathrm{C}\right)$, тогда как для ПП значения $T_{\text {пл }}$ в смесях ниже на $3.1-4.8^{\circ} \mathrm{C}$, чем у исходного полимера $\left(168.8^{\circ} \mathrm{C}\right)$, что подтверждается результатами работы [12].

На термограммах ДСК смесей ПП-СВМПЭ в режиме охлаждения фиксируется один пик (Рис. 3) и, соответственно, одна температура кристаллизации (от 113.2 до $113.7^{\circ} \mathrm{C}$ для смесей различного состава), причем указанные значения занимают промежуточное положение между значениями $T_{\text {кр }}$, соответствующими каждому из полимерных компонентов: СВМПЭ $\left(112.7^{\circ} \mathrm{C}\right)$ и ПП $\left(116.7^{\circ} \mathrm{C}\right)$ (Табл. 2).

Следует отметить, что границы пика, характеризующего процесс кристаллизации полимерной фазы, смещены в область более низких температур по сравнению с исходным ПП (т.е. в область кристаллизации, близкой к СВМПЭ). Наличие одного пика кристаллизации на термограмме объясняется близостью температурных интервалов кристаллизации для исследуемых полимерных компонентов (Табл. 2).

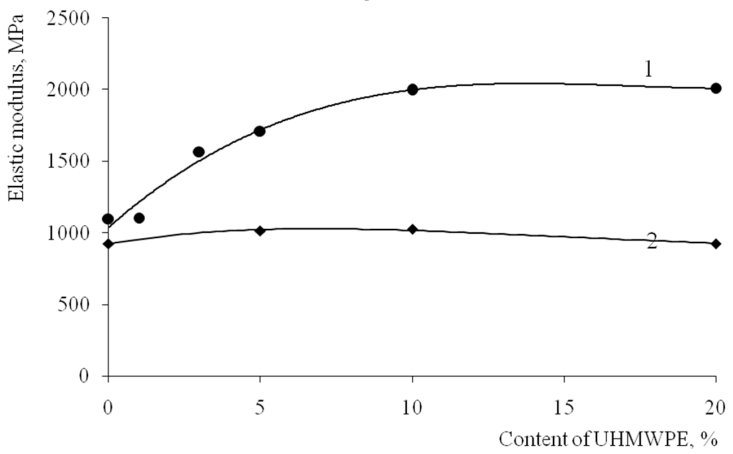

Рис. 2. Зависимость модуля упругости при разрыве (1) и изгибе (2) от содержания СВМПЭ в композите.

Fig. 2. The dependence of the elastic modulus at break (1) and bending (2) on the content of UHMWPE in the composite.

В зависимости от состава полимерной смеси наблюдается существенное изменение значений энтальпии плавления, соответствующих каждому полимерному компоненту. С увеличением содержания ПП в смеси от 10 до 50 мас.\% величина $\left|\Delta H_{\text {пл }}\right|$, соответствующая СВМПЭ, закономерно снижается с 170.6 до 77.7 Дж/г, тогда как значение указанного параметра, соответствующее ПП, напротив, увеличивается от 6.1 до 38.0 Дж/г (Табл. 2). Суммарное значение энтальпий плавления двух полимерных компонентов (СВМПЭ и ПП) в смеси снижается с 176.7 до 115.7 Дж/г (Табл. 2), что, очевидно, обусловлено уменьшением степени кристалличности полимеров.

Аналогичным образом изменяется энтальпия кристаллизации полимерной смеси: с ростом содержания

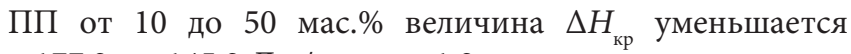
с 177.2 до 145.2 Дж/г, т.е. в 1.2 раза, причем энтальпия кристаллизации компаунда с низким содержанием ПП (10 мас.\%) даже несколько выше, чем исходного СВМПЭ (Табл. 2).

Наличие двух пиков плавления на ДСК-термограммах смесей ПП-СВМПЭ указывает на то, что указанные полимерные компоненты образуют отдельные фазы, т.е. несовместимы, а полимерная система является гетерофазной. Увеличение содержания одного из компонентов (в данном случае ПП) в смеси сопровождается снижением энтальпии плавления второго компонента (СВМПЭ) и уменьшением энтальпии кристаллизации компаунда в целом, что может указывать на затруднение фазовых переходов в системе. 
Табл. 2. Результаты ДСК-анализа композитов ПП-СВМПЭ.

Table 2. DSC analysis of PP-UHMWPE composites.

\begin{tabular}{|c|c|c|c|c|c|c|c|c|}
\hline \multirow{2}{*}{$\begin{array}{l}\text { Содержание СВМПЭ, мас.\% } \\
\text { The content of UHMWPE, wt.\% }\end{array}$} & \multicolumn{2}{|c|}{$\begin{array}{l}T_{\text {nлл }},{ }^{\circ} \mathrm{C} \\
T_{\text {melt }},{ }^{\circ} \mathrm{C} \\
\end{array}$} & \multicolumn{2}{|c|}{$\begin{array}{c}\Delta H_{\text {пл }}, \text { Дж/г } \\
\Delta H_{\text {melt }}, J / g \\
\end{array}$} & \multicolumn{2}{|c|}{$\begin{array}{l}T_{\mathrm{kp}},{ }^{\circ} \mathrm{C} \\
T_{\mathrm{cr}},{ }^{\circ} \mathrm{C} \\
\end{array}$} & \multicolumn{2}{|c|}{$\begin{array}{c}\Delta H_{\mathrm{kp}}, \text { Дж/г } \\
\Delta H_{\mathrm{cr}}, \mathrm{J} / \mathrm{g} \\
\end{array}$} \\
\hline & 1 & 2 & 1 & 2 & 1 & 2 & 1 & 2 \\
\hline 0 & - & 168.8 & - & -90.2 & - & 116.7 & - & 106.7 \\
\hline 100 & 135.7 & - & -180.4 & - & 112.7 & - & 175.6 & - \\
\hline 90 & 135.5 & 164.8 & -170.6 & -6.1 & \multicolumn{2}{|c|}{113.7} & \multicolumn{2}{|c|}{177.2} \\
\hline 80 & 136.7 & 164.0 & -134.2 & -7.7 & \multicolumn{2}{|c|}{113.2} & \multicolumn{2}{|c|}{167.0} \\
\hline 60 & 135.0 & 164.8 & -99.2 & -28.4 & \multicolumn{2}{|c|}{113.8} & \multicolumn{2}{|c|}{149.2} \\
\hline 50 & 136.0 & 165.7 & -77.7 & -38.0 & \multicolumn{2}{|c|}{113.3} & \multicolumn{2}{|c|}{145.2} \\
\hline
\end{tabular}
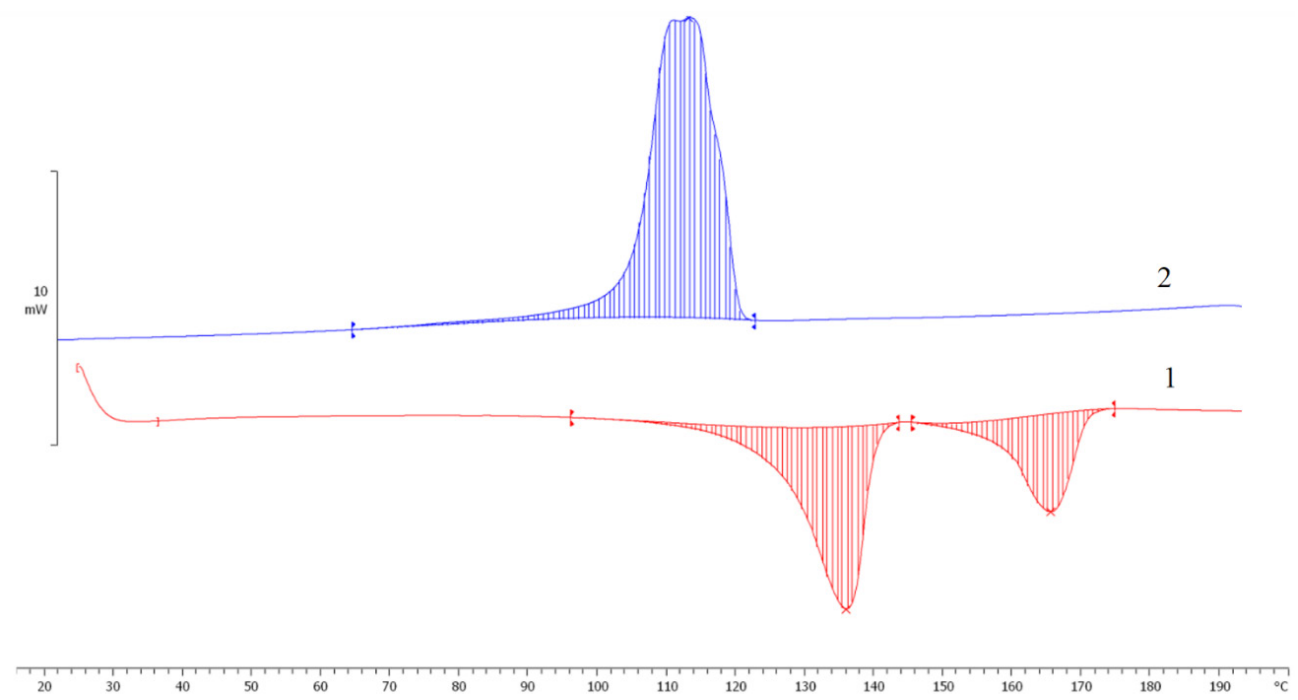

Pис. 3. (Color online) Термограмма ДСК композита, содержащего 50 мас.\% СВМПЭ. Кривая нагрева (1), охлаждения (2). Fig. 3. (Color online) Thermogram DSC of the composite containing $50 \mathrm{wt}$ \% UHMWPE. Curve of heating (1), cooling (2).

\section{4. Заключение}

Величина механического сопротивления, оказываемого системой ПП-СВМПЭ на вращение шнеков в смесительной камере пластографа в процессе пластикации (плавления) полимеров, неаддитивно зависит от состава полимерной смеси. Рост максимального крутящего момента более чем в 2 раза наблюдается при наполнении вторичного полипропилена 5 мас.\% СВМПЭ и только на 25-35\% снижается при наполнении СВМПЭ полипропиленом в количестве 10-50 мас.\% Наполнение вторичного полипропилена СВМПЭ незначительно упрочняет композицию (прочность при разрыве повышается на 3-5\% при содержании СВМПЭ до 3 мас.\%), а также повышает модуль упругости при разрыве и изгибе. Использование в составе композитов на основе вторичного полипропилена добавки сверхвысокомолекулярного полиэтилена способствует повышению термостабильности компаунда, что проявляется в увеличении температуры начала разложения на $12^{\circ} \mathrm{C}$, массы остатка при нагреве до $400^{\circ} \mathrm{C}$, смещении пиков, соответствующих максимальной скорости разложения основного вещества в высокотемпературную область. На термограмме ДСК в режим нагрева наблюдается два эндотермических пика, соответствующих температуре плавления исходных поли- меров, что обусловлено отсутствием термодинамической совместимости исходных полимеров в смеси, при этом температура плавления полипропилена в компаунде на $3.1-4.8^{\circ} \mathrm{C}$ ниже, чем у индивидуального полимера. Кристаллизация ПП и СВМПЭ в смеси протекает в одном температурном диапазоне и характеризуется наличием одного экзотермического максимума на кривой ДСК, который смещен в область температуры, соответствующей кристаллизации СВМПЭ. Наблюдается снижение энтальпии плавления и кристаллизации в смеси полимеров, что может быть обусловлено уменьшением степени кристалличности как ПП, так и СВМПЭ.

Благодарность/Acknowledgements. Исследование выполнено в рамках государственного задания Министерства науки и высшего образования Российской Федерации (проект № FZWU-2020-0027). / The reported study was founded by the Ministry of Science and Higher Education of the Russian Federation (project No. FZWU-2020-0027).

\section{Литература/References}

1. R. B. Salikhov, M.V. Bazunova, A.A. Bazunova, T. R. Salikhov, V.P. Zakharov. Letters on Materials. 8 (4), 485 (2018). Crossref 
2. A.R. Sadritdinov, R.Y. Lazdin, E.M. Zakharova, A.S. Shurshina, V.P. Zakharov, E.I. Kulish. Letters on Materials. 8 (4), 406 (2018). Crossref

3. T. Unger, L. Klocke, K. Herrington, J. Miethlinger. Polymer Testing. 86, 106442 (2020). Crossref

4. N. A. Patil, J. Njuguna, B. Kandasubramanian. European Polymer Journal. 125, 109529 (2020). Crossref

5. Y. Wei, Z. Li, X. Liu, K. Dai, G. Zheng, C. Liu, J. Chen, C. Shen. Colloid and Polymer Science. 292 (11), 2891 (2014). Crossref

6. K.H. Lee, T.K. Sinha, K.W. Choi, J.S. Oh. Journal of Applied Polymer Science. 137, 48720 (2019). Crossref

7. S. Han, T. Zhang, Y. Guo, C. Li, H. Wu, S. Guo. Polymer. 182, 121819 (2019). Crossref

8. F. Guo, H. Jiang, H. Lü, Y. Yin. Journal of Beijing Institute of Technology (English Edition). 28 (3), 667 (2019). Crossref

9. J. Wang, C. Cao, X. Chen, S. Ren, D. Yu, X. Chen. Polymer. 169, 36 (2019). Crossref

10. J. Luo, Y. Liu, Y. Fu, J. Xie. Hecheng Shuzhi Ji Suliao/China Synthetic Resin and Plastics. 26 (1), 57 (2009).

11. S. V. Panin, D. G. Buslovich, L. A. Kornienko, Yu. V. Dontsov,
L. R. Ivanova. Fundamental problems of modern materials science. 16 (3), 377 (2019). (in Russian) [C.В. Панин, Д.Г. Буслович, Л.А. Корниенко, Ю.В. Донцов, Л.Р. Иванова. Фундаментальные проблемы современного материаловедения. 16 (3), 377 (2019).] Crossref

12. E. M. Lee, H. M. Jeong, B. K. Kim. Journal of Macromolecular Science. Part B: Physics. 49 (5), 854 (2010). Crossref

13. S. V. Panin, L.A. Kornienko, M.A. Poltaranin, T. Mandoung, L.R. Ivanova. Mechanical and tribotechnical characteristics of nanocomposites based on mixture of ultrahigh molecular weight polyethylene and polypropylene/Advanced Materials Research. 872, 36 (2015). Crossref

14. V.M. Egorov, V.A. Marikhin, L.P. Myasnikova, A. K. Borisov, E. M. Ivankova, S. S. Ivanchev. Solid State Physics. 61 (10), 1965 (2019). (in Russian) [В. М. Егоров, В.А. Марихин, Л.П. Мясникова, А.К. Борисов, Е. М. Иванькова, С.С. Иванчев. Физика твердого тела. 61 (10), 1965 (2019).] Crossref

15. X. Zhang, Y. Tan, Y. Li, G. Zhang. Plastics, Rubber and Composites. 47 (7), 315 (2018). Crossref 